\title{
Transformation of Ecological Sanitation (Eco-san) and Urine Diversion Dry Toilet (UDDT): the gaps and problems. A review
}

\author{
Govinda Prasad Devkota ${ }^{1}$, Sheri Lee Bastien ${ }^{2}$ \\ PhD Research Scholar, Tribhuvan University, Nepal ${ }^{1}$ \\ Associate Professor of Public Health, Norwegian University of Life Sciences (NMBU), Norway ${ }^{2}$
}

\begin{abstract}
:
This paper highlights the gaps and problems on source separation of human excreta, implementing and adopting human urine as nutrients from sanitation to agriculture. The objective of the paper is to appraise the historical context behind the promotion of Urine Diversion Dry toilet (UDDT)/Eco-san toilets and its relevance in Nepalese context, highlight its status, share the experiences regarding agricultural perspectives and livelihood, understand and analyze the major issues, challenges, gaps/ problems in acceptance and use it in Nepal for scaling up and way out knowledge transformation regarding UDDTs/ Eco-san toilets as agricultural nutrients and sanitation through school education system. Specifically, this paper focus on urine diversion to demonstrate its potential to elegantly separate, collect and concentrate products that we require(nutrients) and those that we wish to regulate (pathogens and micro-pollutants). There is an urgent need for increased school and community participation to address users' perceptions, attitudes and behavior concerning the UDDT.
\end{abstract}

Keywords: Eco-san/UDDT, Nutrients, Participatory Action Research (PAR), Transformative Education 